\title{
C-A-S-H Gel and Pore Structure Characteristics of Alkali-Activated Red Mud-Iron Tailings Cementitious Mortar
}

\author{
Chao Li, Na Zhang *, Jiancong Zhang, Shuai Song and Yihe Zhang * \\ Beijing Key Laboratory of Materials, Utilization of Nonmetallic Minerals and Solid Wastes, \\ National Laboratory of Mineral Materials, School of Materials Science and Technology, \\ China University of Geosciences, Beijing 100083, China; SleeQaQ@126.com (C.L.); zjc1321695230@126.com (J.Z.); \\ 18600771568@163.com (S.S.) \\ * Correspondence: nazhang@cugb.edu.cn (N.Z.); zyh@cugb.edu.cn (Y.Z.)
}

Citation: Li, C.; Zhang, N.; Zhang, J.; Song, S.; Zhang, Y. C-A-S-H Gel and Pore Structure Characteristics of Alkali-Activated Red Mud-Iron Tailings Cementitious Mortar. Materials 2022, 15, 112. https:// doi.org/10.3390/ma15010112

Academic Editor: Dolores Eliche Quesada

Received: 30 November 2021 Accepted: 18 December 2021 Published: 24 December 2021

Publisher's Note: MDPI stays neutral with regard to jurisdictional claims in published maps and institutional affiliations.

Copyright: (C) 2021 by the authors. Licensee MDPI, Basel, Switzerland. This article is an open access article distributed under the terms and conditions of the Creative Commons Attribution (CC BY) license (https:// creativecommons.org/licenses/by/ $4.0 /)$.

\begin{abstract}
Red mud and iron tailings are representative solid wastes in China, which have caused serious environmental pollution and potential harmful risk to people. Based on the alkali characteristic of Bayer red mud and natural fine-grained feature of iron tailings, these two solid wastes were used as raw materials to prepare alkali-activated cementitious mortar (AACM). The microstructure of C-A-S-H gel, pore structure characteristics, environmental impact and economic potential of this AACM were investigated. The results show that C-A-S-H gel was mainly composed of $\mathrm{SiQ}^{3}$ structure in the 28-day cured AACM. The relative content of $\mathrm{SiQ}^{4}$ structure increased while that of $\mathrm{SiQ}^{2}$ structure decreased as the hydration time advanced from 7 to 28 days, resulting in the increase of relative bridge oxygen value by $11.02 \%$. The pores in the AACM sample accounted for $6.73 \%$ of the total volume, and these pores were not connected. The pore distribution was relatively uniform, which supported the good development of mechanical strength for AACM. This research elucidates the formation mechanism of C-A-S-H gels in the Bayer red mud-iron tailings-based AACM. In addition, the lower embodied carbon and material cost demonstrate that the prepared AACM has great environmental benefit and certain economic potential.
\end{abstract}

Keywords: strength development verification; reaction product; SEM-EDS analysis; relative bridge oxygen; embodied carbon

\section{Introduction}

Red mud is a kind of industrial solid waste produced in the process of extracting alumina from bauxite. Its main chemical components are $\mathrm{SiO}_{2}, \mathrm{Al}_{2} \mathrm{O}_{3}, \mathrm{CaO}, \mathrm{Fe}_{2} \mathrm{O}_{3}, \mathrm{Na}_{2} \mathrm{O}$, and $\mathrm{TiO}_{2}$. Every one ton of alumina is produced with the discharge of 1.0-1.8 tons of red mud. Because red mud contains high alkali content, its piling up in large quantities can seriously cause environmental pollution [1,2], such as land alkalinization and groundwater pollution, which will inevitably affect people's health. As a major producer of alumina, China emits millions of tons of red mud each year [3]. Most red mud is stored in open air without any effective use. According to statistics, China's alumina production in 2018 is about 69 million tons [4]. If the red mud produced by per ton of alumina is calculated as 1.45 tons, China's red mud production in 2018 is about 100 million tons. Just as other solid wastes need to be disposed with detoxification and solidification, such as municipal solid waste incineration fly ash [5], the hazardous components of red mud also need to be disposed of, and the heavy metals need to be solidified and stabilized before it can be used. With the problem of red mud stacking and its pollution to the environment becoming more and more serious, it is extremely urgent to utilize red mud to the maximum extent.

As an industrial solid waste generated in the process of iron ore beneficiation, iron tailings discharge more than 10 billion tons of tailings and waste rocks every year in the world [6]. Over the past thirty years, with the rapid development of China's iron and steel industry, iron tailing has become one of the main industrial solid wastes in China. 
By 2015, China has produced 5 billion tons of iron tailings, with a yearly discharge of more than 600 million tons, accounting for $1 / 3$ of the total tailings reserves $[7,8]$. The massive accumulation of iron tailings leads to the waste of land resources, which greatly increases the possibility of environmental pollution $[9,10]$. The residual ions of flotation agent in iron tailings enter the surrounding fields and rivers with rainwater, which will cause serious pollution to the environment. Some harmless components in the tailings occur, i.e., differentiation, fragmentation, and various chemical reactions in nature, and the soluble ions generated will pollute the environment to some extent. Therefore, the resource utilization of iron tailings has been widely concerned by the whole society.

Alkali-activated cement (AAC) is a kind of inorganic cementitious material with threedimensional net-like structure composed of $\mathrm{AlO}_{4}$ and $\mathrm{SiO}_{4}$ tetrahedral structure units. This material has excellent mechanical properties and performances of acid and alkaline resistance, fire resistance, and high temperature resistance [11]. It can use silica-aluminabased mineral waste and construction waste as raw materials. Because AAC is a new cementitious material with promising application prospect, it has been used far and wide in the field of building materials. Over the past twenty years, there has been much research on AAC using red mud or iron tailings as raw materials. Liu et al. [12] used Bayer red mud and coal metakaolin as raw materials, $\mathrm{NaOH}$ and sodium silicate as alkali activators to prepare AAC with 28-day compressive strength up to $56.2 \mathrm{MPa}$ by adjusting $\mathrm{Na} / \mathrm{Al}$ molar ratio to be 1.0. Their research shows that the increase of $\mathrm{Na} / \mathrm{Al}$ molar ratio in a certain range is conducive to the development of pore structure, and finally leads to the improvement of mechanical properties. However, the continuous increase of $\mathrm{Na} / \mathrm{Al}$ molar ratio will lead to the alkalinity of AAC and destroy the microstructure of AAC. Koshy et al. [13] used red mud, coal gangue and fly ash after silicate activation treatment as raw materials to prepare AAC. Their study found that the ternary mixture of coal gangue, fly ash and red mud had a higher strength than the binary mixture of coal gangue and red mud at a lower curing temperature. Duan et al. [14] used iron tailings and fly ash as raw materials to prepare AAC. The effects of temperature and times of thermal cycling, and the proportion of iron tailings on the properties of AAC were studied. Their results show that addition of iron tailings optimized the surface Vickers-hardness of the AAC, and the thermal resistance of AAC was significantly improved with the replacement level of iron tailings less than $30 \%$, and replacing fly ash with $20 \%$ iron tailings would obtain a much denser microstructure because of the reduction of porosity and micro-crackings. Defáveri et al. [15] used iron tailings and glass wool residue as raw materials to prepare AAC with compressive strength higher than $100 \mathrm{MPa}$ and flexural strength higher than $20 \mathrm{MPa}$. They found that C-S-H gel existed in the iron tailings-based AAC. Moreover, using iron tailings as main raw material and metakaolin as correction raw material, Chen et al. [16] prepared AAC with 28-day compressive strength up to $59.0 \mathrm{MPa}$ by alkali activation. By conducting orthogonal experiments, they concluded that $\mathrm{Si} / \mathrm{Al}$ ratio of raw materials had the greatest influence on early strength of iron tailingsmetakaolin-based AAC among all factors, and liquid-solid ratio had the greatest influence on the final strength. They found that geological polymerization and hydration reactions were carried out simultaneously in the iron tailings-metakaolin-based AAC, and some mineral crystalline phases gradually changed into amorphous structure. The main phase of iron tailings-metakaolin-based AAC was amorphous silicoaluminate, semi-crystalline $\mathrm{CSH}$ (I) and $\alpha-\mathrm{C}_{2} \mathrm{SH}$, and the gelatinous substance cemented the fine particles together to form a compact gel body, which made the AAC have a high compressive strength. Besides, Wang et al. [17] also found that the $\mathrm{Si} / \mathrm{Al}$ ratio had a great influence on the properties of geopolymer, and the varied $\mathrm{Si} / \mathrm{Al}$ ratio resulted in different structures, properties, and efflorescence degree of the fly ash-based AAC.

Although there have been many studies on the preparation of AAC from red mud or iron tailings, there are still few studies on the preparation of AAC by using both these two solid wastes as raw materials. Most of iron tailings are ground into powder as siliconaluminum-based precursors to participate in the AAC reaction. There are few studies on preparation of AAC from unground iron tailings. Our research group has made a new 
attempt to produce red mud-iron tailing-based alkali-activated mortar and investigated the mechanical properties and environmental stability performance including resistances to acid, alkali, and sulfate attacks as well as freeze-thaw cycling of the red mud-iron tailing-based alkali-activated mortar [18]. It was found that the best performance was attained for the alkali-activated mortar composed of $16 \%$ Bayer red mud powder and $75 \%$ iron tailing aggregate. Based on the previous study, the present work is a further deep investigation on the C-A-S-H gel formation mechanism and pore structure characteristics of Bayer red mud-iron tailings-based alkali-activated cementitious mortar (AACM). In this research, Fourier transform infrared spectroscopy (FT-IR), ${ }^{29} \mathrm{Si}$ nuclear magnetic resonance (NMR), and scanning electron microscopy combined with energy dispersive spectroscopy (SEM-EDS) were applied to obtain useful information on the phase identification, $\mathrm{SiO}_{4}$ polymerization degree, micro-morphology, and element composition of C-A-S-H gels in the Bayer red mud-iron tailings-based AACM. Computed tomography (X-CT) technique was employed to analyze the pore structure of this AACM. Moreover, environmental impact and economic potential of this AACM were evaluated. The paper is hoped to provide a corresponding theoretical support for the large-scale industrial utilization of iron tailings and red mud in the production of AAC.

\section{Materials and Methods}

\subsection{Materials}

The main raw materials for preparing AACM in this study are Bayer red mud, blast furnace slag powder, and iron tailings. Besides, a small amount of 52.5 Portland cement was added to provide calcium-based precursor. Table 1 shows the chemical composition and origin information of the relevant raw materials used in this work. As the most important raw materials, Figure 1 shows XRD patterns of Bayer red mud and iron tailings. It presents that the main mineralogical phases of Bayer red mud are cancrinite, katoite, and hematite. The main minerals composed in the iron tailings are ferropargasite, clinochlore, and anorthite.

Table 1. Chemical composition and origin information of raw materials.

\begin{tabular}{|c|c|c|c|c|}
\hline $\begin{array}{c}\text { Chemical } \\
\text { Constitution/\% }\end{array}$ & Red Mud & Iron Tailings & Slag Powder & $\begin{array}{l}\text { 52.5 Portland } \\
\text { Cement }\end{array}$ \\
\hline $\mathrm{Al}_{2} \mathrm{O}_{3}$ & 24.66 & 17.87 & 17.3 & 6.05 \\
\hline $\mathrm{SiO}_{2}$ & 20.57 & 36.42 & 32.64 & 21.68 \\
\hline $\mathrm{CaO}$ & 20.86 & 14.21 & 37.66 & 62.86 \\
\hline $\mathrm{Na}_{2} \mathrm{O}$ & 16.16 & 0.94 & 0.5 & 0.2 \\
\hline $\mathrm{Fe}_{2} \mathrm{O}_{3}$ & 7.67 & 16.36 & 0.66 & 3.26 \\
\hline $\mathrm{TiO}_{2}$ & 6.17 & 2.42 & 0.72 & 0.32 \\
\hline $\mathrm{SO}_{3}$ & 1.08 & - & 1.63 & 2.61 \\
\hline $\mathrm{K}_{2} \mathrm{O}$ & 0.62 & 1.08 & 0.76 & 1.09 \\
\hline $\mathrm{MgO}$ & 0.39 & 6.41 & 7.42 & 1.51 \\
\hline Place of origin & $\begin{array}{c}\text { Hejin, Shanxi } \\
\text { Province } \\
\text { of China }\end{array}$ & $\begin{array}{c}\text { Laiyuan, Hebei } \\
\text { Province } \\
\text { of China }\end{array}$ & $\begin{array}{c}\text { Hejin, Shanxi } \\
\text { Province } \\
\text { of China }\end{array}$ & $\begin{array}{l}\text { Conch Cement } \\
\text { Co. Ltd., Anhui } \\
\text { Province } \\
\text { of China }\end{array}$ \\
\hline
\end{tabular}

Coarse and fine iron tailings with different particle size were used in this research. The particle size of coarse iron tailings is distributed within 3-5 mm. Figure 2 shows laser particle size distributions of Bayer red mud and fine iron tailings. As can be seen from Figure $2 a$, the particle size of red mud is relatively small, and it is mainly distributed within the range of $0.3-120 \mu \mathrm{m}$. The particle size of fine iron tailings is relatively larger than that of red mud, and its particle size is mainly distributed within the range of 21-1028 $\mu \mathrm{m}$. 
a

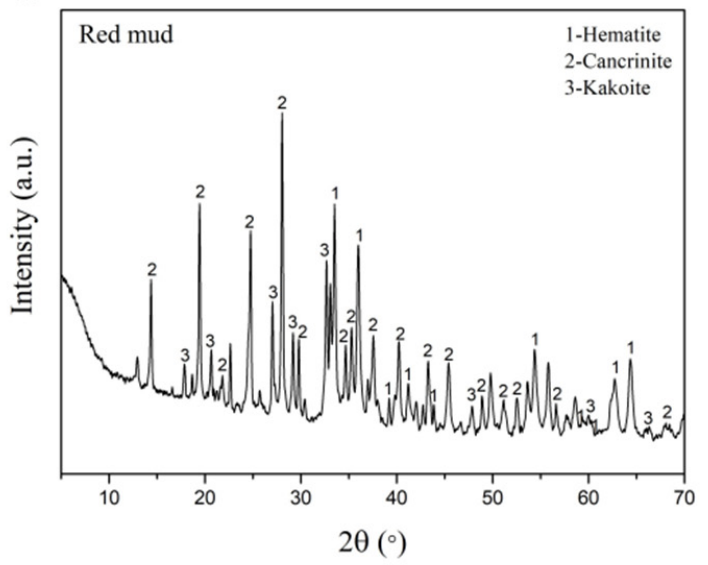

$\mathrm{b}$

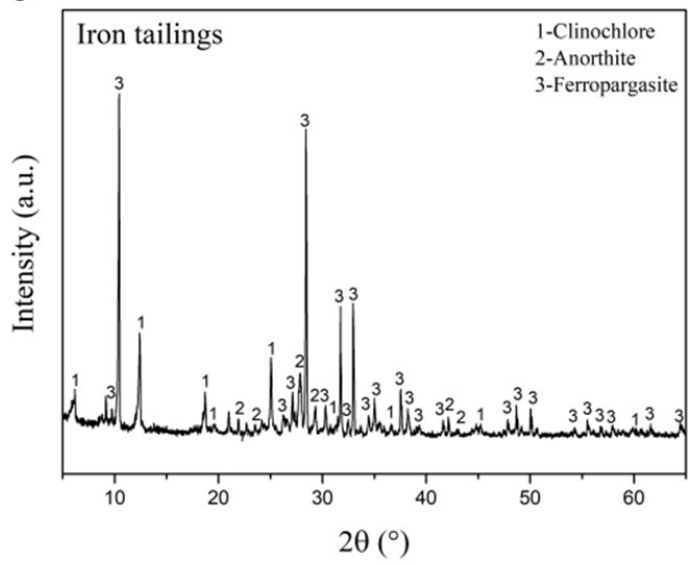

Figure 1. XRD patterns of Bayer red mud (a) and iron tailings (b).
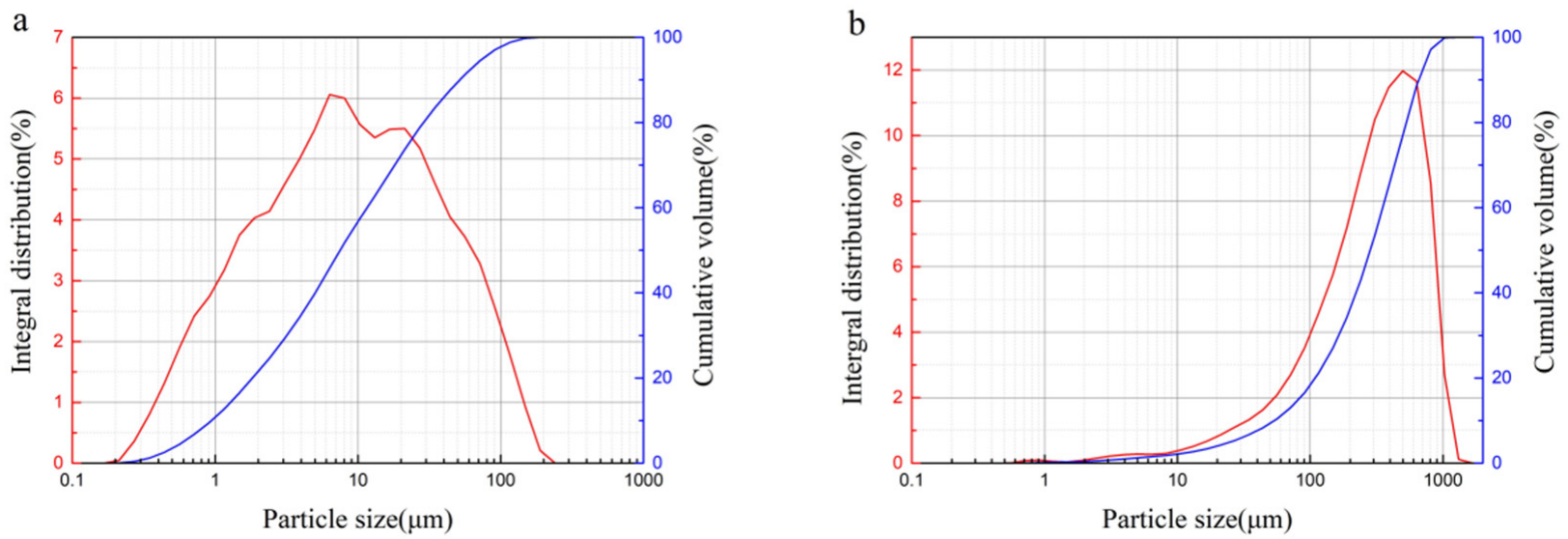

Figure 2. Laser particle size distribution of Bayer red mud (a) and fine iron tailings (b).

\subsection{Preparation of $A A C M$}

The AACM was prepared by mixing the Bayer red mud, iron tailings, blast furnace slag powder, 52.5 Portland cement, alkali activator and water together. The mass proportions of Bayer red mud, iron tailings, blast furnace slag powder, and 52.5 Portland cement were $16 \%, 75 \%, 7.5 \%$, and $1.5 \%$, respectively. Sodium silicate was used as alkali activator to participate in the geopolymerization, and the modulus in this work was set to 1.5. In addition, the mass ratio of coarse and fine iron tailings as aggregates was $3: 2$, and the ratio of water to binder was 0.63 . The preparation flow chart of AACM is shown in Figure 3. Firstly, admixtures were added to the blender, then turned on the blender, poured into the sodium silicate and water, and stirred for $30 \mathrm{~s}$ at $62 \mathrm{rpm}$. Secondly, coarse and fine iron tailings were added to the blender and stirred for another $30 \mathrm{~s}$ at $62 \mathrm{rpm}$. Finally, stirring for $90 \mathrm{~s}$ at $125 \mathrm{rpm}$ to complete the mixing of raw materials. The slurry was then poured into a $40 \times 40 \times 160 \mathrm{~mm}$ mortar mold and vibrated for $2 \mathrm{~min}$ to remove the entrapped air from the mixture. To prevent evaporation, the fresh mortar should be covered with plastic wrap. After $24 \mathrm{~h}$, they were demolded at room temperature and then cured in a constant temperature and humidity curing box with a temperature of $20 \pm 2{ }^{\circ} \mathrm{C}$ and a humidity of $90 \%$. 

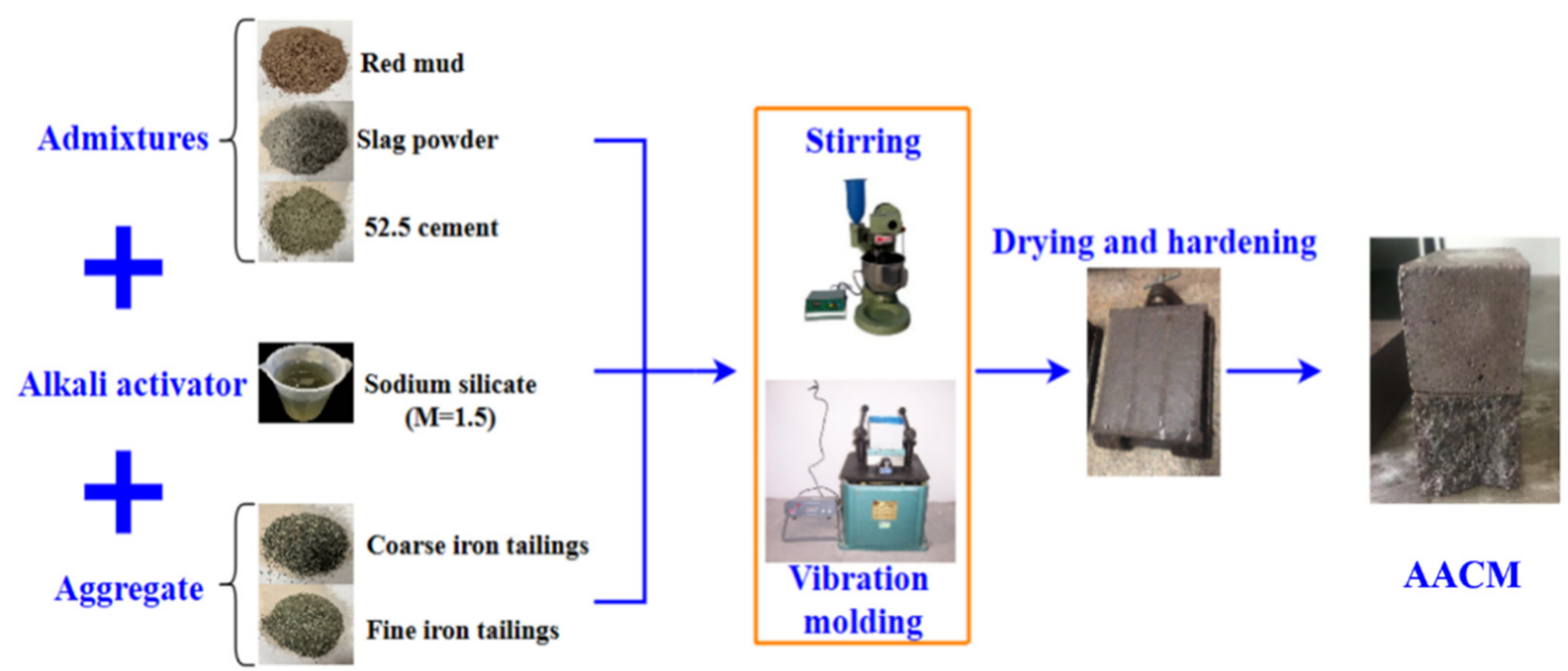

AACM

Figure 3. Preparation flow chart of AACM.

\subsection{Testing and Characterization}

X-ray powder diffractometer (D8 ADVANCE, Bruker Corporation, Massachusetts, America) is used for mineralogical phase characterization of Bayer red mud and iron tailings. The target source is equipped with $\mathrm{Cu}$ target and $\mathrm{Co}$ target. The diffraction angle range (20) is $5-70^{\circ}$ with scanning rate of $6^{\circ} / \mathrm{min}$. The test temperature is $25^{\circ} \mathrm{C}$, the tube voltage is $20-60 \mathrm{kV}$, and the tube current is $10-60 \mathrm{~mA}$. The samples were analyzed by JADE 6.0 software. X-ray fluorescence spectrometer (ARLAdvantX Intellipower TM3600, Thermo Fisher Scientific, Waltham, MA, USA) is used to analyze chemical composition of Bayer red mud, iron tailings, blast furnace slag powder, and 52.5 Portland cement. Laser particle size distribution instrument (Bettersize2000, Dandong Baxter Instrument Co., Ltd., Dandong, China) is used to test the particle size distribution of Bayer red mud and fine iron tailings.

Compressive strength and flexural strength of AACM specimens were tested according to Test Method for Strength of Cement Mortar (ISO method) (GB/T17671-1999) [19] when the curing time reached 3, 7 and 28 days. The flexural strength and compressive strength are two important mechanical performance indexes of AAC material. In this study, the devices used to test the flexural strength and compressive strength are motorized bending tester (KZJ-500, Shenyang Great Wall Electromechanical Equipment Factory, Shenyang, China) and electro-hydraulic servo universal testing machine (WAW-2000E, Jinan Koohei Test Machine Co., Ltd., Jinan, China), respectively.

Characterization tests including SEM-EDS, FT-IR, NMR, and X-CT techniques were performed on the AACM specimens cured for 7 and 28 days. Before these characterization tests, it is required to carry out a series of treatments for the samples. After curing for 7 and 28 days, the AACM samples were immersed in anhydrous ethanol for $72 \mathrm{~h}$ to stop the hydration process, and then the samples were dried in a vacuum drying oven at $60^{\circ} \mathrm{C}$ for $24 \mathrm{~h}$. Finally, some of the samples were ground into powder by electromagnetic sample grinder for FT-IR and NMR analysis, and the other samples without grinding were directly taken for SEM and X-CT analysis.

Field emission scanning electron microscope (SEM, SU8020, Hitachi Ltd., Tokyo, Japan) is used to observe the micromorphology of AACM specimens. Before taking SEM image, the AACM samples need to be treated with golden sputtering.

Infrared spectrometer (Nicolet IS10, Thermo Nicolet Corporation, Madison, GA, USA) is used for FT-IR test. Through analyzing the infrared spectrum of sample, the absorption band can be used to determine the functional groups to determine the corresponding chemicals and alkali reaction products of AACM. 
The equipment used for solid nuclear magnetic resonance testing is $600 \mathrm{M}$ solid nuclear magnetic resonance instrument (Agilent 600M, Agilent Technologies Inc., Santa Clara, CA, USA). The amount of powdered sample used for NMR testing should be more than $0.5 \mathrm{~g}$. After completion of the NMR test, MestReNova software was used to analyze and process the test data. Through analysis of ${ }^{29} \mathrm{Si}$ NMR spectrum of AACM, the $\mathrm{SiO}_{4}$ structure unit and relative bridge oxygen (RBO) value of hydration product can be obtained, and then the change rule of $\mathrm{SiO}_{4}$ polymerization degree of AACM with hydration time can be understood.

Three dimensional CT scanner (NanoVolex 4000, Tianjin Sanying Precision Instrument Co., Ltd., Tianjin, China) is used to test the pore structure of AACM. One picture with a size of $1920 \times 1536$ was collected at an interval of $0.25^{\circ}$. We improved the resolution of 2880 images by rotating the sample twice during the test. Other experimental parameters are presented in Table 2. The reconstruction software Voxel Studio Recon was used to carry out the algorithm reconstruction, image correction, and processing of the scanned data after the completion of the test. Then, Volume Graphics Studio Max, FEI Avizo, SYPISore and other software were used to carry out image display, measurement, digital core analysis, and other processing on the reconstructed data of the sample. The sample also needs to be processed before the test. After curing for 7 days, the AACM sample with size of $40 \times 40 \times 160 \mathrm{~mm}$ was cut into a cube specimen with size of $30 \times 30 \times 30 \mathrm{~mm}$. The specimen was immersed in anhydrous ethanol for $72 \mathrm{~h}$ to stop the hydration process, and then dried in a vacuum oven at $60{ }^{\circ} \mathrm{C}$ for $24 \mathrm{~h}$.

Table 2. Experimental parameters of X-CT test.

\begin{tabular}{cccccc}
\hline Sample & Resolution/ $\boldsymbol{\mu m}$ & Voltage/kV & $\begin{array}{c}\text { Current } \\
\text { Flow/ } \boldsymbol{\mu A}\end{array}$ & $\begin{array}{c}\text { Time of } \\
\text { Exposure/s }\end{array}$ & $\begin{array}{c}\text { Scanning } \\
\text { Time/min }\end{array}$ \\
\hline AACM & 30.53 & 190 & 130 & 0.65 & 90 \\
\hline
\end{tabular}

\section{Results and Discussion}

\subsection{Strength Development of the AACM}

The flexural and compressive strengths of AACM with hydration time are shown in Figure 4a. With the increase of hydration time, the flexural strength and compressive strength of AACM also increase. At 3 days of hydration, the flexural strength and compressive strength of the specimen reached values of 4.68 and $16.88 \mathrm{MPa}$, respectively, and then they reached 7.28 and $29.74 \mathrm{MPa}$ after 28 days of hydration. Compared with our previous work [18], the strength development of this AACM is slower than that of sample $\mathrm{AB}$ presented in the preliminary work. As the origins of red mud, iron tailings, and blast furnace slag have changed in this work, the different chemical and mineralogical compositions of red mud and iron tailings result in the strength difference. However, the 28-day flexural and compressive strengths are similar, which can basically attain 7 and $30 \mathrm{MPa}$. It is thought that the produced AACM is appropriate for road repair because of its high early strength. Furthermore, this AACM is prepared with large proportions of solid wastes (red mud, iron tailings, and blast furnace slag) as raw material, which can not only relieve the accumulation pressure of solid wastes, but also save cost and potentially produce huge economic benefits. 


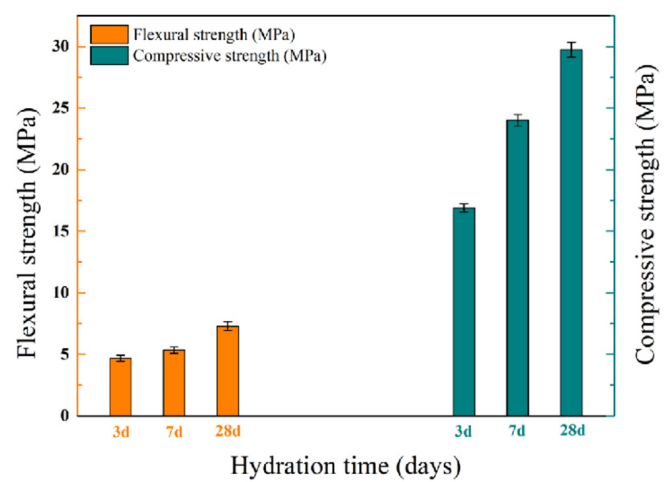

b

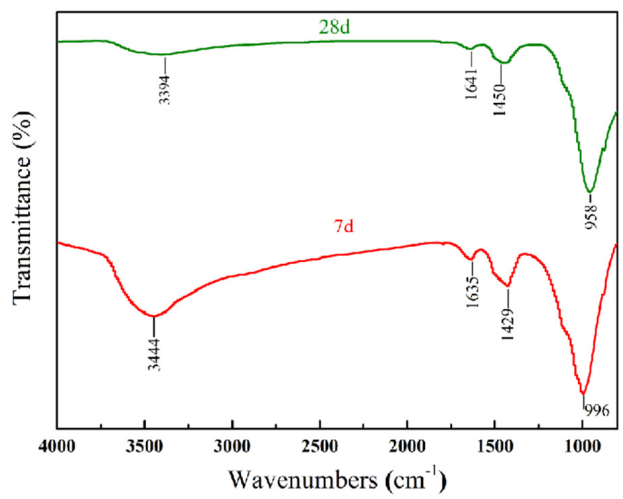

c
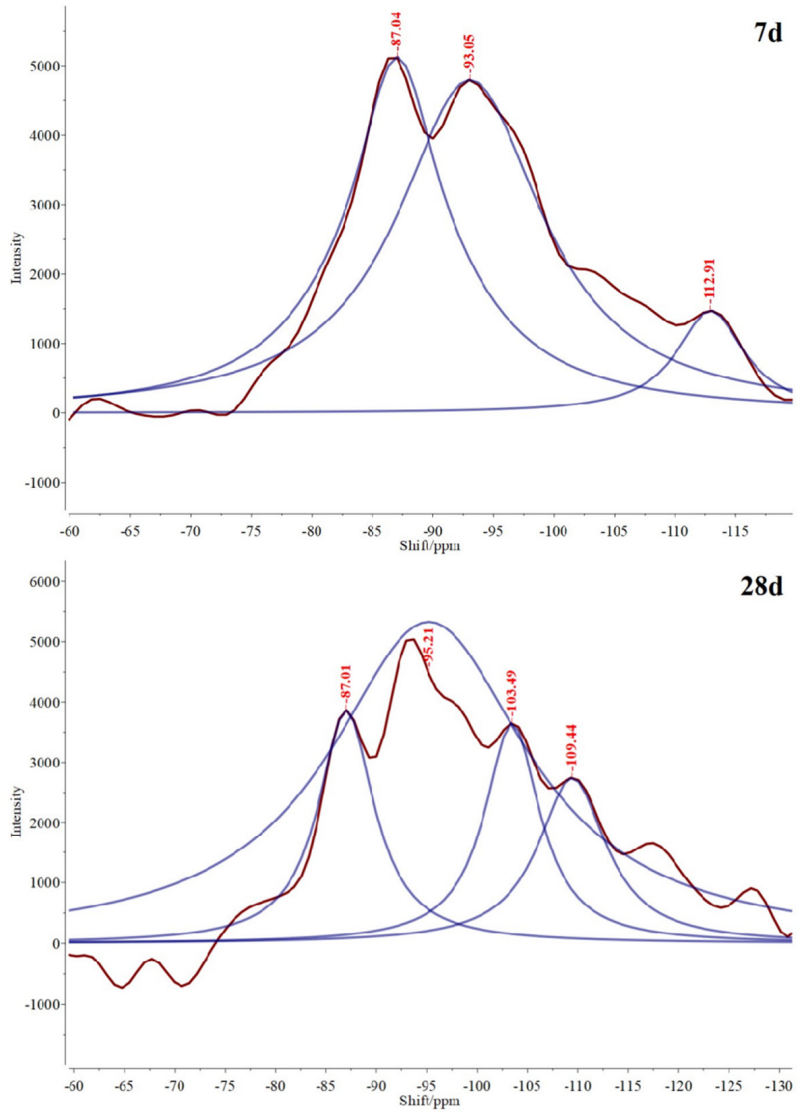

Figure 4. Flexural and compressive strengths (a), FI-IR spectra (b), and ${ }^{29} \mathrm{Si} \mathrm{MAS} \mathrm{NMR} \mathrm{spectra} \mathrm{(c)} \mathrm{of}$ AACM hydrated for 7 and 28 days.

\subsection{C-A-S-H Gels Formation in the AACM}

\subsubsection{FT-IR Analysis}

Figure $4 \mathrm{~b}$ shows FT-IR spectra of AACM specimens hydrated for 7 and 28 days. The spectral bands of specimens hydrated for 7 days and 28 days are similar. The absorption peaks with wavenumber at 1429 and $996 \mathrm{~cm}^{-1}$ are the characteristic spectral bands of C-A-S-H gel $[18,20,21]$. It proves that the reaction product of this AACM is mainly C-A-S-H gel. The spectral band at $996 \mathrm{~cm}^{-1}$ is put down to the anti-symmetric stretching vibration of $\mathrm{Si}-\mathrm{O}-\mathrm{Si}(\mathrm{Al})$ in the $\mathrm{Si}(\mathrm{Al}) \mathrm{O}_{4}$ tetrahedral structure of C-A-S-H gel. The wide absorption spectral band at $3444 \mathrm{~cm}^{-1}$ represents stretching vibration of Al-OH in the cancrinite of red mud. The peak decreases when the specimen hydrates for 28 days, which indicates that $\mathrm{Al}-\mathrm{OH}$ in the red mud participates in the polymerization reaction to form more C-A-S-H gels. The absorption spectral band at $1635 \mathrm{~cm}^{-1}$ represents $\mathrm{H}-\mathrm{O}-\mathrm{H}$ bending vibration for interlayer water [22,23]. As the hydration time increases, free water participates in the hydration process and gradually changes into crystal water.

\subsection{2. ${ }^{29} \mathrm{Si}$ NMR Analysis}

Figure $4 \mathrm{c}$ shows ${ }^{29} \mathrm{Si}$ NMR spectra of AACM specimens hydrated for 7 and 28 days. ${ }^{29} \mathrm{Si}$ NMR can provide information about the relative amount of silicon atoms in different $\mathrm{Q}^{\mathrm{n}}(\mathrm{mAl})(\mathrm{n}=0-4)$ tetrahedra environments, where $\mathrm{n}$ represents the number of bridge oxygen between $\mathrm{SiO}_{4}$ tetrahedrons, and the number of aluminum atoms around $\mathrm{SiO}_{4}$ tetrahedron is represented by $\mathrm{m}$ [24]. Through the analysis of ${ }^{29} \mathrm{Si}$ NMR spectrum, the polymerization degree of aluminum-silicate chain can be obtained. Therefore, the formula 
for calculating the relative bridge oxygen ( $\mathrm{RBO}$ ) number that can effectively evaluate the polymerization degree of $\mathrm{SiO}_{4}$ is summarized [25]):

$$
\mathrm{RBO}=\frac{1}{4}\left(1 \times \frac{\mathrm{Q}^{1}}{\sum \mathrm{Q}^{\mathrm{n}}}+2 \times \frac{\mathrm{Q}^{2}}{\sum \mathrm{Q}^{\mathrm{n}}}+3 \times \frac{\mathrm{Q}^{3}}{\sum \mathrm{Q}^{\mathrm{n}}}+4 \times \frac{\mathrm{Q}^{4}}{\sum \mathrm{Q}^{\mathrm{n}}}\right)=\frac{1}{4} \times \frac{\sum \mathrm{n} \cdot \mathrm{Q}^{\mathrm{n}}}{\sum \mathrm{Q}^{\mathrm{n}}}
$$

$\mathrm{Q}^{\mathrm{n}}$ : Relative area of the formant.

The research of Puertas et al. [26] states that the peaks at -77 to $-82 \mathrm{ppm}$ corresponds to $\mathrm{SiQ}^{1}$ unit, and the peaks near $-85 \mathrm{ppm}$ corresponds to $\mathrm{SiQ}^{2}$ unit. The peak near -82 to $-84 \mathrm{ppm}$ is related to $\mathrm{SiQ}^{2}(1 \mathrm{Al}) / \mathrm{SiQ}^{2}(0 \mathrm{Al})$, which is mainly due to the signal moving from 3-5 ppm to more positive values by replacing Si with Al. Besides, the chemical shift from -92 to $-100 \mathrm{ppm}$ is associated with $\mathrm{SiQ}^{3}$ unit, and the peak near $-88 \mathrm{ppm}$ to $-91 \mathrm{ppm}$ is related to $\mathrm{SiQ}^{3}(2 \mathrm{Al}) / \mathrm{SiQ}^{3}$ (1Al). The peaks at -103 to $-115 \mathrm{ppm}$ corresponds to $\mathrm{SiQ}^{4}$ unit. According to the data in Table 3, it can be known that the C-A-S-H gels in the AACM specimen hydrated for 7 days are mainly composed of $\mathrm{SiQ}^{3}$ and $\mathrm{SiQ}^{2}$ units, while they mainly contain $\mathrm{SiQ}^{3}$ structure at 28 days. The $\mathrm{RBO}$ value of the 28 -day sample increases by $11.02 \%$ compared with that of the 7 -day specimen. It indicates that the extension of the hydration time leads to the increase of $\mathrm{SiO}_{4}$ tetrahedron polymerization degree for the C-A-S-H gels. After hydrated for 28 days, the structure of C-A-S-H gels become more complicated with $\mathrm{SiQ}^{4}$ structure increased and $\mathrm{SiQ}^{2}$ structure decreased.

Table 3. RBO calculation results of C-A-S-H gels of AACM hydrated for 7 and 28 days.

\begin{tabular}{ccccc}
\hline & \multicolumn{2}{c}{$\mathbf{7 ~ d}$} & \multicolumn{2}{c}{$\mathbf{2 8 ~ d}$} \\
\cline { 2 - 5 } Structural Unit & $\begin{array}{c}\text { Chemical Shift } \\
\text { (ppm) }\end{array}$ & Relative Area & $\begin{array}{c}\text { Chemical Shift } \\
\text { (ppm) }\end{array}$ & Relative Area \\
\hline $\mathrm{SiQ}^{2}$ & -87.0 & 79.4 & -87.0 & 20.33 \\
$\mathrm{SiQ}^{3}$ & -93.0 & 100 & -95.2 & 100 \\
$\mathrm{SiQ}^{4}$ & -112.9 & 14.4 & -103.5 & 19.13 \\
$\mathrm{RBO}$ & & $66.59 \%$ & -109.4 & $77.61 \%$ \\
\hline
\end{tabular}

\subsubsection{SEM-EDS Analysis}

Figures 5 and 6 show the SEM morphologies of AACM specimens hydrated for 7 and 28 days, respectively. The SEM analysis results show that the cementitious substance of AACM in this work is mainly reticular gel. In addition, it can be seen that the iron tailings particles are embedded in the gel matrix and bonded by the gels, indicating that the iron tailings aggregates are closely connected and cemented by the reticular gels.

The results of EDS analysis on the reticular gels occurring in the AACM specimens hydrated for 7 and 28 days are shown in Table 4 . As the reticular gels contain $\mathrm{Ca}, \mathrm{Si}$ and $\mathrm{Al}$ elements, it can be firmly determined that the reaction product of this AACM is C-A-S-H gel. This result is in accordance with the above FT-IR analysis result and the observation reported by Ding et al. [27]. In addition, according to the data in Table 4, it can be known that with the prolongation of hydration time, the content of $\mathrm{Al}$ and $\mathrm{Na}+\mathrm{K}$ in the $\mathrm{C}-\mathrm{A}-\mathrm{S}-\mathrm{H}$ gel at 28 days increases significantly compared with that at 7 days, and the content of $\mathrm{Si}$ and $\mathrm{Ca}$ decreases correspondingly. Owing to the substitution of $\mathrm{Si}$ by $\mathrm{Al}$ in the C-A-S-H gel, the number of $\mathrm{AlO}_{4}$ connected with $\mathrm{SiO}_{4}$ increases with the extension of hydration time, and on this basis, the number of monovalent cations (such as $\mathrm{Na}^{+}$and $\mathrm{K}^{+}$) that attracted for solidification due to the charge vacancy also increases correspondingly. The efflorescence degree can be obviously reduced by the dense matrix and $\mathrm{AlO}_{4}$ structures of AAC [17]. In our previous work reported by Song et al. [18], the main products generated in the 28-days cured red mud-iron tailings-based AACM are C-A-S-H gels and calcium aluminum iron silicate hydroxide $\left(\mathrm{Ca}_{3} \mathrm{AlFe}\left(\mathrm{SiO}_{4}\right)(\mathrm{OH})_{8}\right)$. However, except the main product of C-A-S-H gel, calcium aluminum iron silicate hydroxide is not found in the present work. It is noticed that the Bayer red mud used in our previous work contains 
$46.61 \% \mathrm{Fe}_{2} \mathrm{O}_{3}$, while the red mud used in the present study only contains $7.67 \% \mathrm{Fe}_{2} \mathrm{O}_{3}$. Although cancrinite is composed in the present red mud, the much lower content of $\mathrm{Fe}_{2} \mathrm{O}_{3}$ is insufficient to support the replacement of $\mathrm{Al}$ by Fe for the transformation of cancrinite to form $\mathrm{Ca}_{3} \mathrm{AlFe}\left(\mathrm{SiO}_{4}\right)(\mathrm{OH})_{8}$.

Table 4. EDS analysis results of C-A-S-H gel (atomic percentage/\%).

\begin{tabular}{ccc}
\hline Chemical Element & $\mathbf{7 ~ d}$ & $\mathbf{2 8} \mathbf{~ d}$ \\
\hline $\mathrm{O}$ & 41.30 & 51.35 \\
$\mathrm{Al}$ & 4.44 & 6.86 \\
$\mathrm{Si}$ & 17.71 & 15.17 \\
$\mathrm{Ca}$ & 26.85 & 17.85 \\
$\mathrm{Na}+\mathrm{K}$ & 1.04 & 2.88 \\
\hline
\end{tabular}

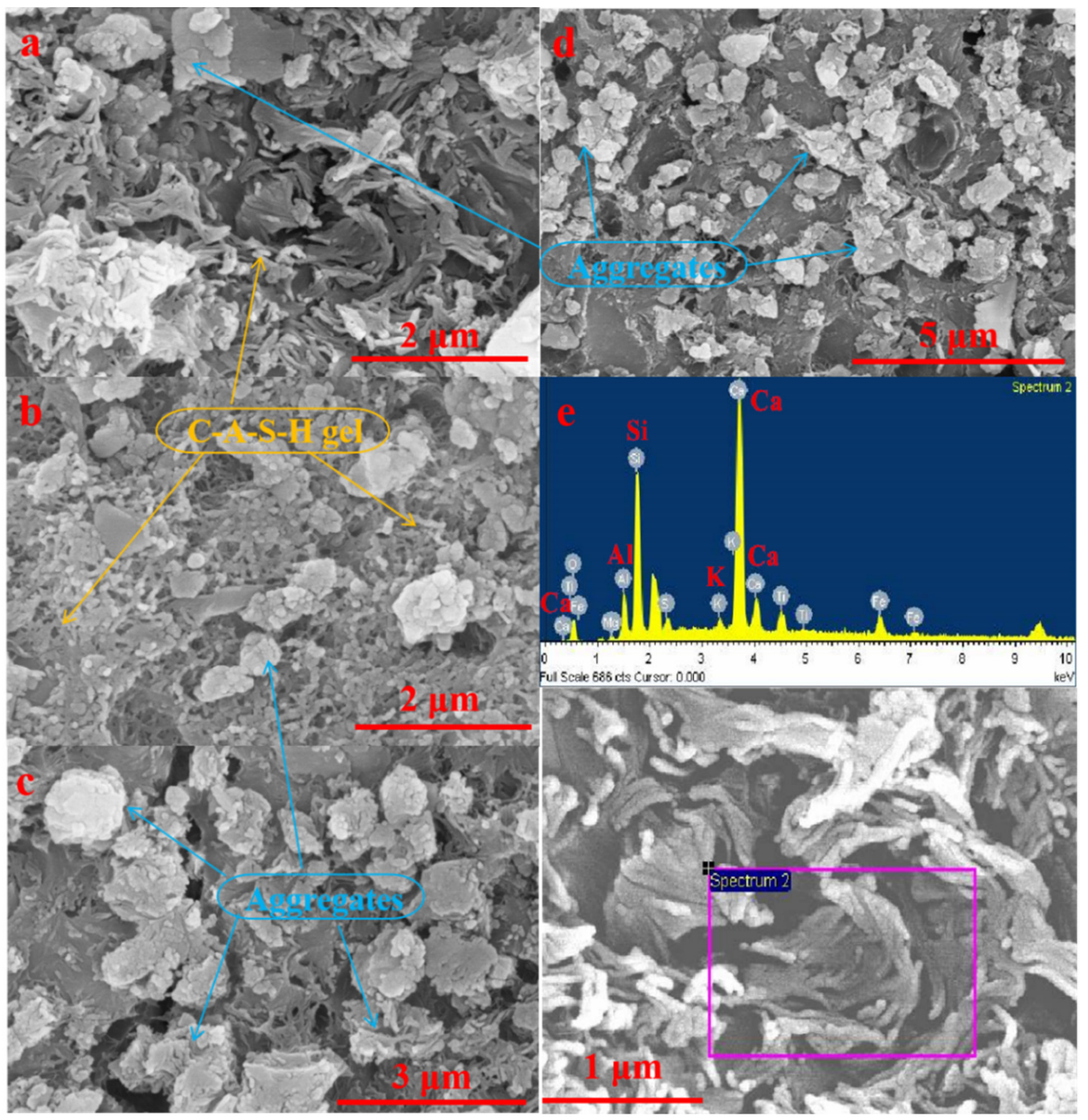

Figure 5. SEM morphology (a-d) and EDS analysis (e) of C-A-S-H gels in the AACM after 7 days of hydration. 


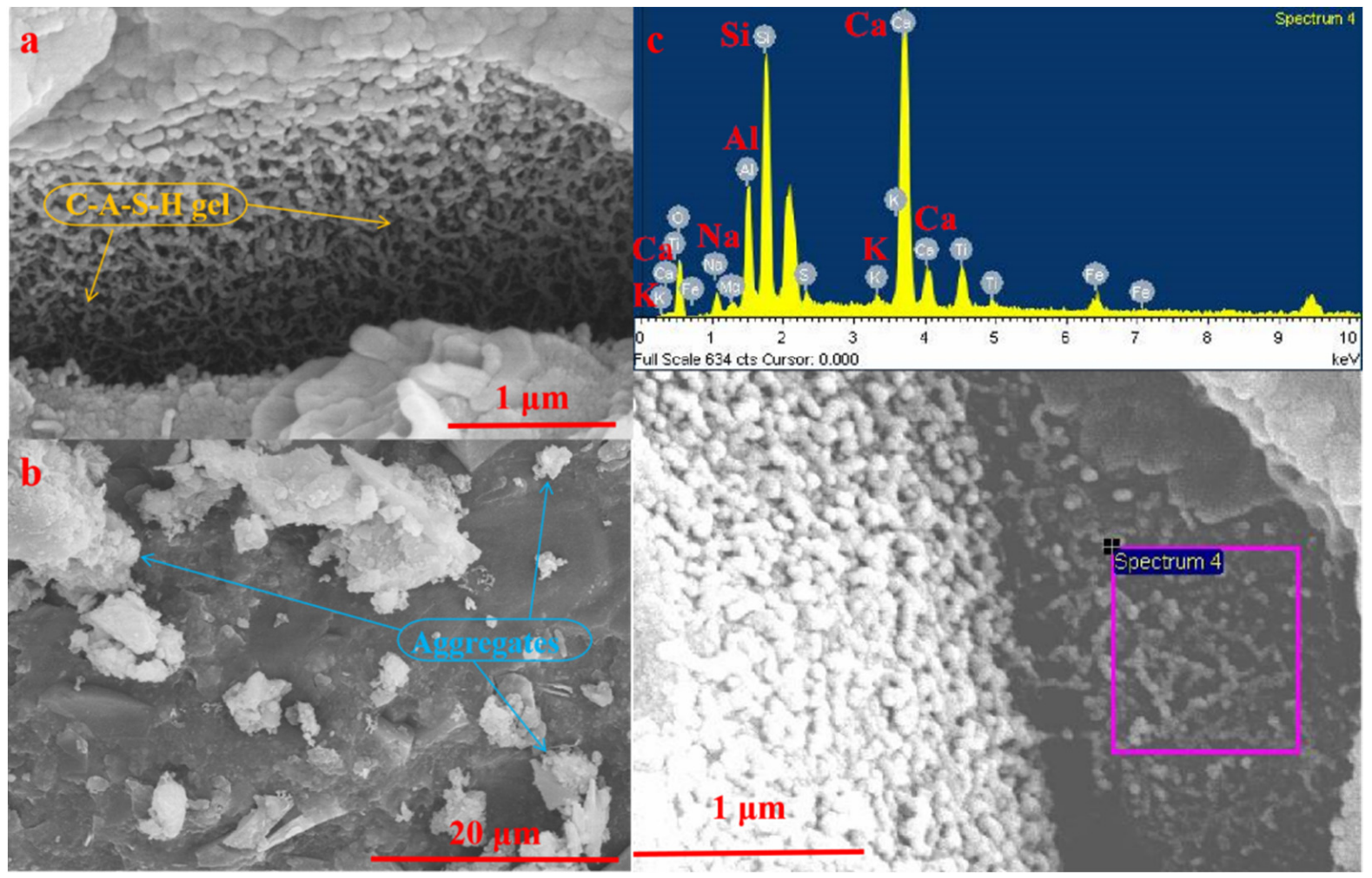

Figure 6. SEM morphology (a,b) and EDS analysis (c) of C-A-S-H gels in the AACM after 28 days of hydration.

\subsubsection{Formation Mechanism of C-A-S-H Gel in the AACM}

Red mud and blast furnace slag powder adopted in this study are silica-alumina precursors, which are the key materials to prepare AACM. 52.5 Portland cement acts as the calcium-silica precursor to catalyze the geopolymerization process. The alkaliactivated reaction product of this AACM is mainly amorphous C-A-S-H gel, which plays an important part in facilitating the densification of the AACM structure [28-30]. The formation process of C-A-S-H gel in this AACM can be expressed as the following, the schematic diagram of which is shown in Figure 7.

$$
\begin{gathered}
\mathrm{SiO}_{2}+\mathrm{OH}^{-}+\mathrm{H}_{2} \mathrm{O} \rightarrow\left[\mathrm{H}_{3} \mathrm{SiO}_{4}\right]^{-} \\
\mathrm{AlO}_{2}{ }^{-}+\mathrm{OH}^{-}+\mathrm{H}_{2} \mathrm{O} \rightarrow\left[\mathrm{H}_{3} \mathrm{AlO}_{4}\right]^{2-} \\
{\left[\mathrm{H}_{3} \mathrm{SiO}_{4}\right]^{-}+\left[\mathrm{H}_{3} \mathrm{AlO}_{4}\right]^{2-}+\mathrm{Ca}^{2+} \rightarrow \mathrm{C}-\mathrm{A}-\mathrm{S}-\mathrm{H}}
\end{gathered}
$$

The active siliceous substances in red mud, blast furnace slag powder, and iron tailings are uniformly represented by $\mathrm{SiO}_{2} \cdot \mathrm{AlO}_{2}{ }^{-}$represents the active aluminum substances dissolved from red mud, blast furnace slag powder, and iron tailings. When the alkaliactivated reaction and hydration begin, the 52.5 Portland cement and sodium silicate solution quickly release ions of $\mathrm{Ca}^{2+}, \mathrm{OH}^{-},\left[\mathrm{H}_{3} \mathrm{SiO}_{4}\right]^{-}$. Under the activation provided by the 52.5 Portland cement and alkali activator, $\left[\mathrm{H}_{3} \mathrm{SiO}_{4}\right]^{-}$and $\left[\mathrm{H}_{3} \mathrm{AlO}_{4}\right]^{2-}$ ions are continuously dissolved from the active $\mathrm{SiO}_{2}$ and $\mathrm{Al}_{2} \mathrm{O}_{3}$ in the red mud, blast furnace slag powder, and the surface of iron tailings. In this blended system, the amorphous C-A-S-H gels are formed by the reaction of $\left[\mathrm{H}_{3} \mathrm{SiO}_{4}\right]^{-}$and $\left[\mathrm{H}_{3} \mathrm{AlO}_{4}\right]^{2-}$ ions with $\mathrm{Ca}^{2+}$, and their structural model is shown in Figure 8 [31-33]. During the hydration reaction, the dissolved $\mathrm{K}^{+}$and $\mathrm{Na}^{+}$in this system can combine with $\left[\mathrm{SiO}_{4}\right]^{4-}$ and $\left[\mathrm{AlO}_{4}\right]^{5-}$ to form transitional substances. As the hydration time increases, the hydration reaction continues, and a large amount of dissolved $\mathrm{Na}^{+}$and $\mathrm{K}^{+}$could be stabilized in the amorphous gel. $\mathrm{Na}^{+}$and $\mathrm{K}^{+}$ play the roles of catalysis and participation in charge balance in this reaction $[34,35]$. As 
the main alkali-activated reaction product, amorphous C-A-S-H gels are not only the main reason for the strength development of AACM, but also conducive to the refinement of the pore size, which makes a dense structure of AACM.

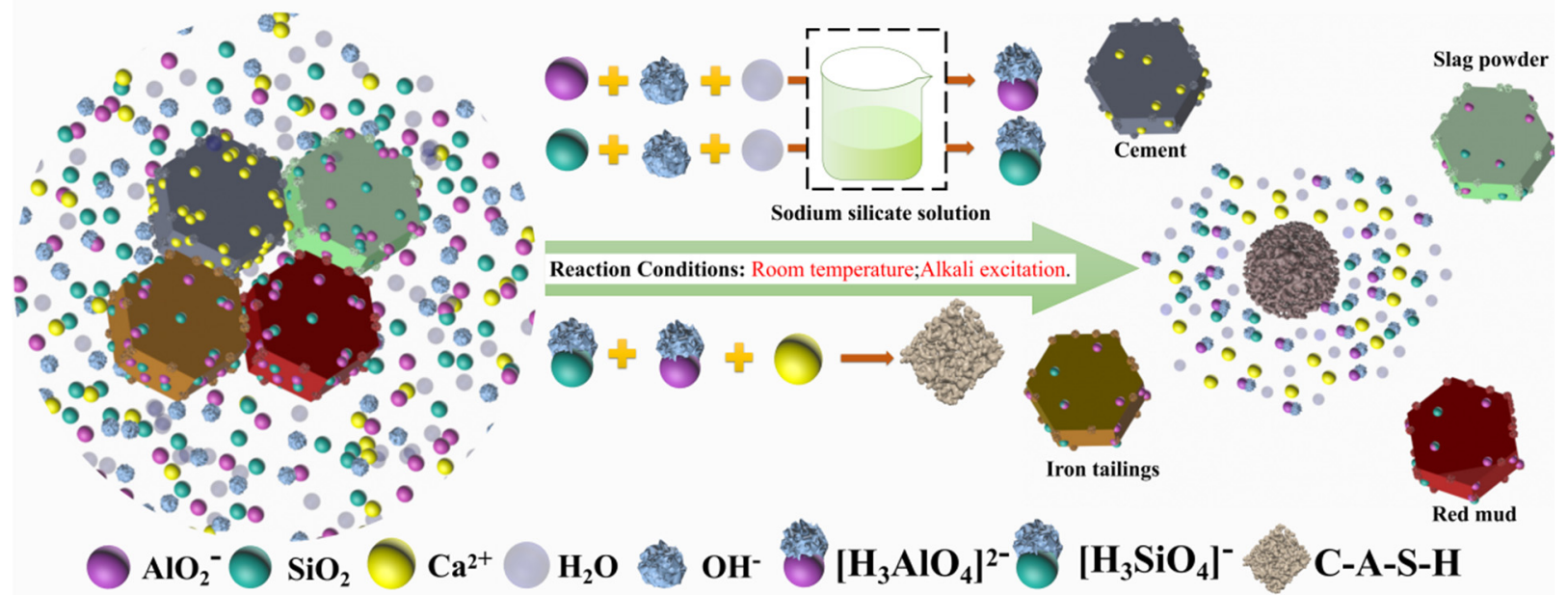

Figure 7. Schematic diagram of the formation of C-A-S-H gels in the AACM.

a

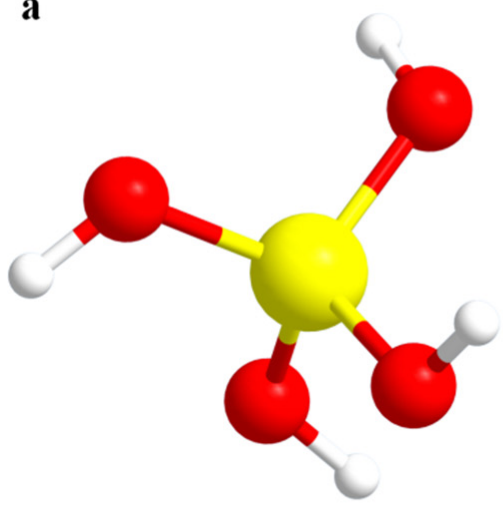

b

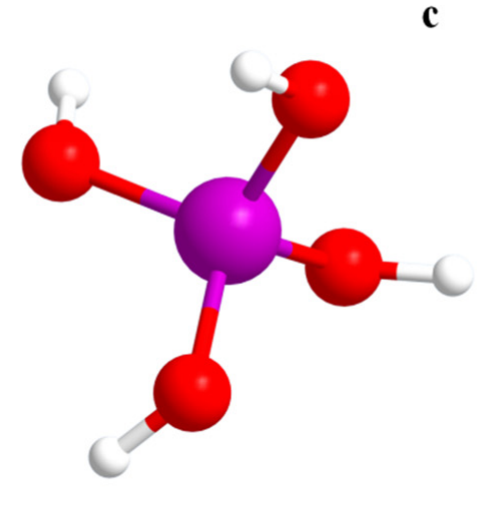

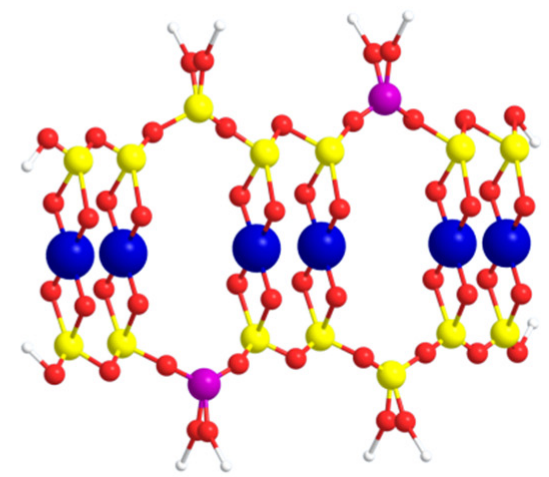

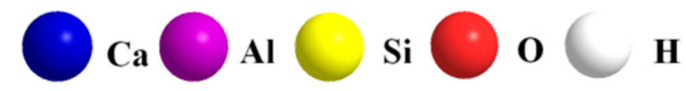

Figure 8. Structural model. ((a): $\left[\mathrm{H}_{3} \mathrm{SiO}_{4}\right]^{-},(\mathbf{b}):\left[\mathrm{H}_{3} \mathrm{AlO}_{4}\right]^{2-}$, and (c): C-A-S-H gel).

\subsection{Pore Structure Characteristics of the AACM}

In order to observe the large pore structure of AACM, NanoVolex 4000 series resolution industrial CT was adopted in this study to scan the hardened AACM specimen that have hydrated for 7 days. Two-dimensional (2D) and three-dimensional (3D) imaging from different directions were applied to scan the sample. The four views of the AACM sample are shown in Figure 9. The distribution of pores and other components can be clearly seen from Figure 9. The black area represents pores, the white light part represents metallic minerals, and the gray part represents aggregates and other matrix materials. Moreover, by scanning the sample slices in $\mathrm{XY}, \mathrm{XZ}$, and $\mathrm{YZ}$ directions, we can further explore whether the pores of AACM are evenly distributed in different directions. According to Figure 10, the pore distribution of AACM is evenly distributed in the above three directions. It can be seen intuitively that the size of pores in the directions of $X Y$ and $X Z$ are larger than those 
in $\mathrm{YZ}$ direction. In general, the presence of large pores is not conducive to the strength development of materials.

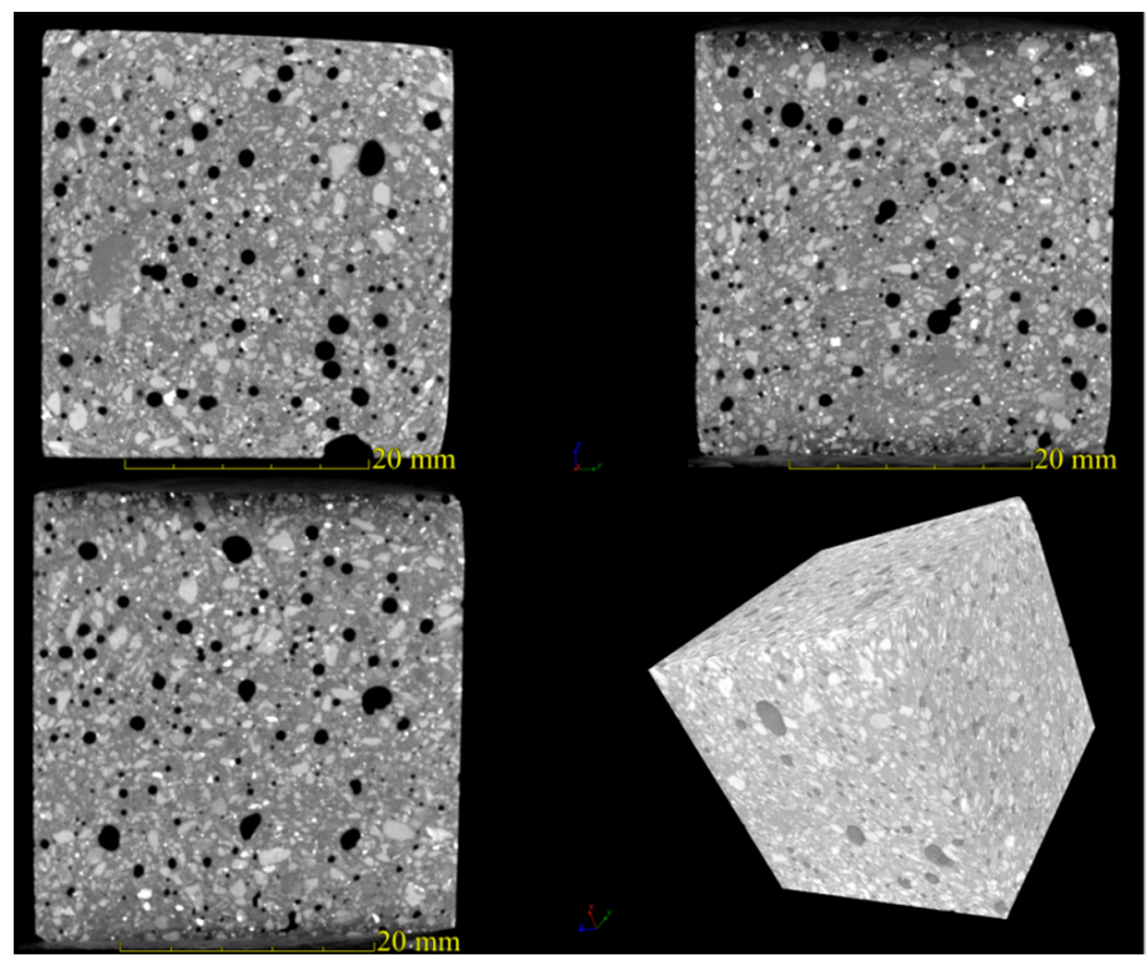

Figure 9. Four views of AACM specimen.

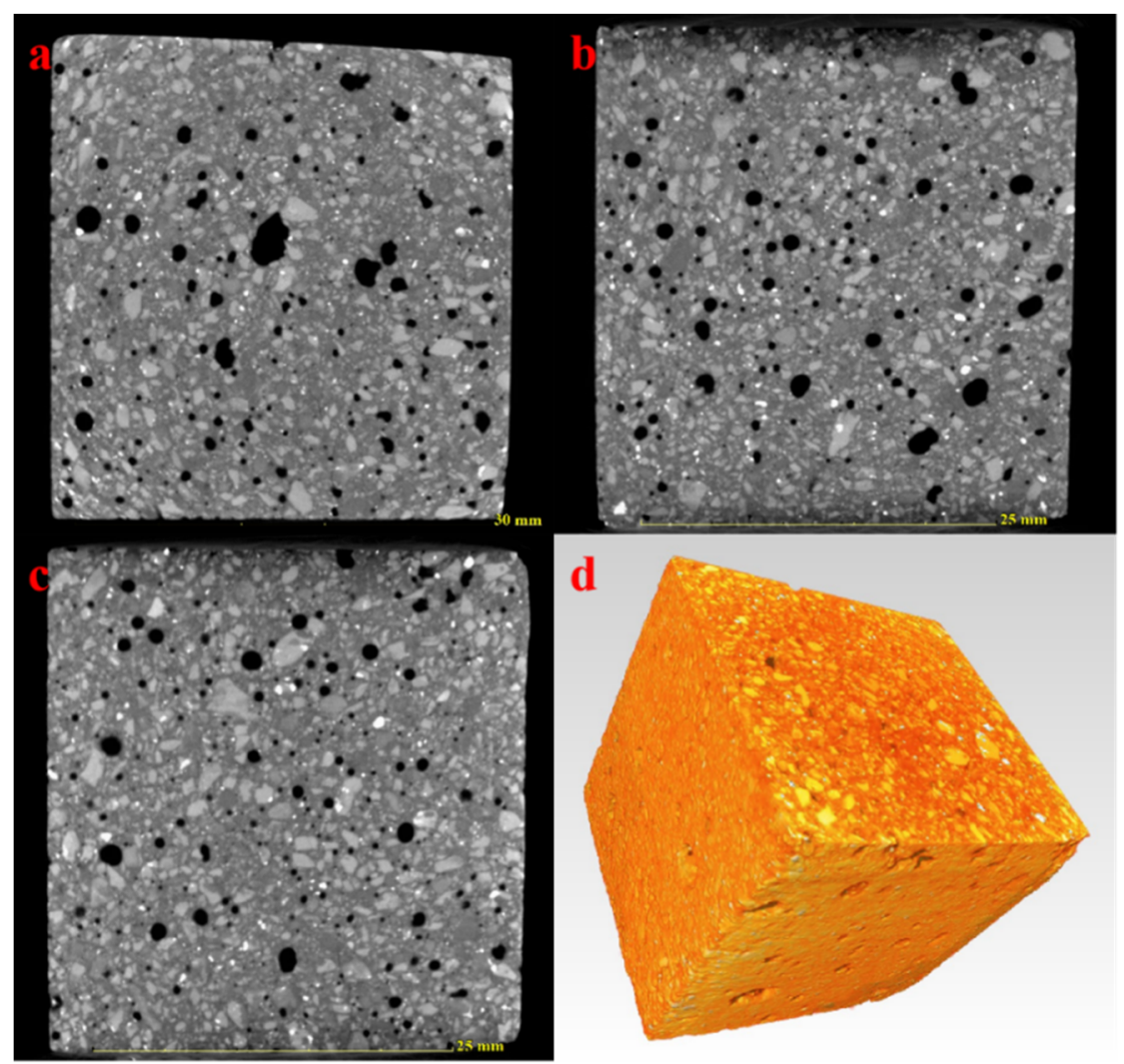

Figure 10. $X Y, X Z, Y Z$ directional slices $(\mathbf{a}-\mathbf{c})$ and $3 D$ scanning image of AACM specimen (d). 
Digital core analysis and threshold segmentation are used for quantitative analysis of the different components of the material in order to understand the pore structure of AACM at a greater distance. The principles and applications of digital core analysis and threshold segmentation have been described in detail in the literature [36,37]. The computer software FEI AVIZO is used to threshold the images of AACM. Figure 11 shows the 3D distribution of pore, mineral, aggregate particle, and other matrix material obtained by processing data. The red substances in Figure 11a represent pores in the sample, and it accounts for $6.73 \%$ of the total volume of AACM specimen. According to Figure 11a, the different pores of the prepared AACM are uniformly distributed, and the pores with small size are in the majority, which is beneficial to improve the mechanical properties of AACM. Furthermore, the yellow, cyan, and blue substances in Figure 11b-d represent minerals, aggregate particles, and other matrix materials, respectively, and they account for $10.98 \%$, $24.71 \%$, and $57.58 \%$ of the total volume, respectively. In the total volume of the specimen, the proportions of aggregate particles and other matrix materials have reached $82.29 \%$, which guarantee the strength requirements of AACM.
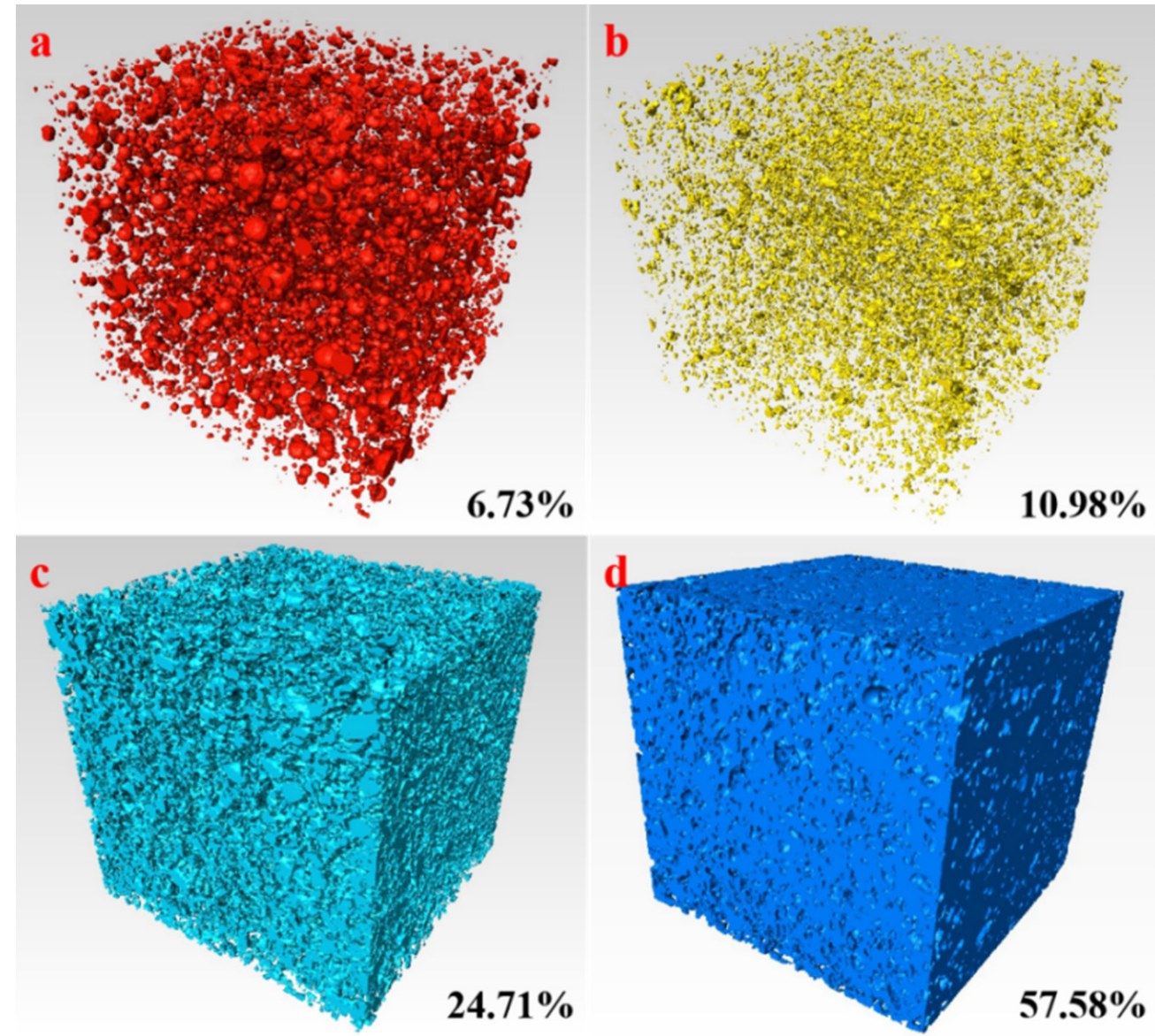

Figure 11. Three dimensional distribution of different components of AACM specimen. ((a): pore, (b): mineral, (c): aggregate particle, and (d): other matrix material).

In order to better understand the pore structure of the AACM sample, it is necessary to use the maximum sphere algorithm to process the pore data obtained from digital core analysis and construct the pore network model. The principles of the maximum sphere algorithm have been described in detail in the literature [36,38]. The parameters of the sample such as pore throat size, coordination number, and shape factor can be obtained by mathematical statistics. The pore throat network model constructed in this study and the related characterization parameters obtained are shown in Figure 12. According to Figure $12 b, d$, the pores and throats of the sample have skewed distributions. Large pores 
and throats are relatively few. The pore radius and throat radius are mainly distributed in 50-100 and 20-60 $\mu \mathrm{m}$, respectively. Figure 12c shows that the pore form factor has a normal distribution, and the main distribution values are 0.02-0.032. According to the relevant introduction of the form factor in the literature [36], it can be concluded that the shape of most of pores and throats in this study area is roughly triangular and irregular. According to Figure 12e, the distribution of throat length in the study area is mainly $60 \mu \mathrm{m}$, indicating that one part of the throat has a high passability. The coordination number is the number of throats connected by a pore. The larger the coordination number, the more the number of throats coordinated with it, and the better the connectivity of the material. As shown in Figure 12f, the maximum coordination number in the study area of AACM sample is 4 , and the average coordination number is 0 . It indicates that the pores in the AACM are not connected.
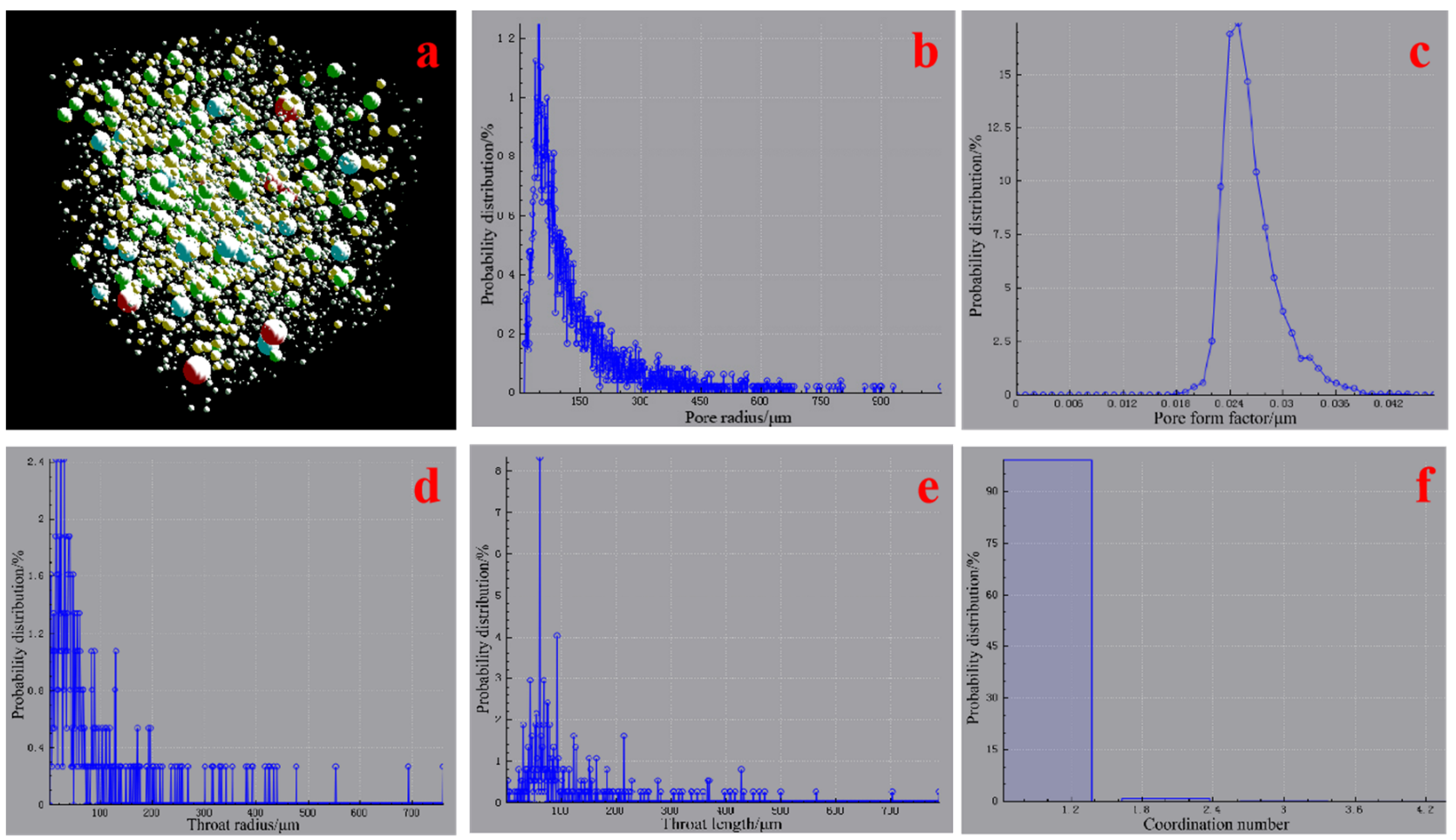

Figure 12. Characterization parameter analysis diagram of AACM specimen. ((a): ball and stick model, $(\mathbf{b})$ : pore radius, $(\mathbf{c})$ : pore form factor, $(\mathbf{d})$ : throat radius, $(\mathbf{e})$ : throat length, and $(\mathbf{f})$ : coordination number).

\subsection{Environmental Impact and Economic Potential of the AACM}

In this study, embodied carbon, an important sustainability parameter, is used to assess the environmental impact of AACM. The embodied carbon of raw materials are calculated based on the cradle-to-gate system, and the calculation method of embodied carbon of AACM comes from the literature [39]. The embodied carbon of the raw materials comes from the statistics of Hammond and Jones [40], and the specific data are presented in Table 5. Among them, the embodied carbon of red mud has not been found, but its embodied carbon is estimated to be almost the same as that of solid waste such as fly ash; thus, it is considered to be less than 0.1 when calculating the total embodied carbon of AACM. In this work, as the 28-day compressive strength of this AACM is about $30 \mathrm{MPa}$, C30 concrete is selected as the reference standard when studying the environmental impact of AACM [41]. 
Table 5. Embodied carbon and market price of raw materials.

\begin{tabular}{ccc}
\hline Material & $\begin{array}{c}\text { Embodied Carbon } \\
(\mathbf{k g ~ C O} / \mathbf{k g})\end{array}$ & Market Price (CNY/Metric ton) \\
\hline Iron tailings & 0.00747 & 100 \\
Red mud & $<0.1$ & 250 \\
52.5 cement & 0.912 & 630 \\
Blast furnace slag & 0.0416 & 300 \\
Sodium silicate & 2.28 & 850 \\
Water & 0.00034 & 4 \\
\hline
\end{tabular}

The comparison chart of the total embodied carbon of AACM and C30 concrete is shown in Figure 13a. The total embodied carbon of AACM is $30.73 \%$ lower than that of C30 concrete. Furthermore, in the total embodied carbon of AACM, the embodied carbon of alkali activator accounted for a large proportion of $71.85 \%$, and the embodied carbon of other raw materials accounted for a small proportion. Therefore, it demonstrates that using red mud, blast furnace slag, and iron tailings to prepare AACM is extremely environmental friendly.

a

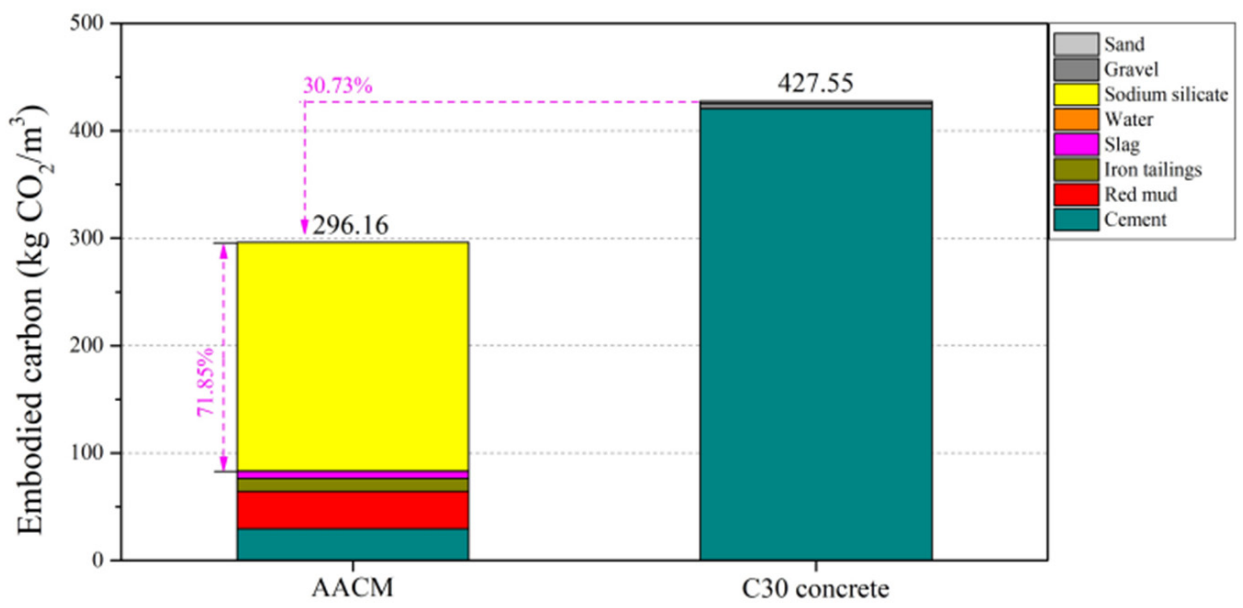

b

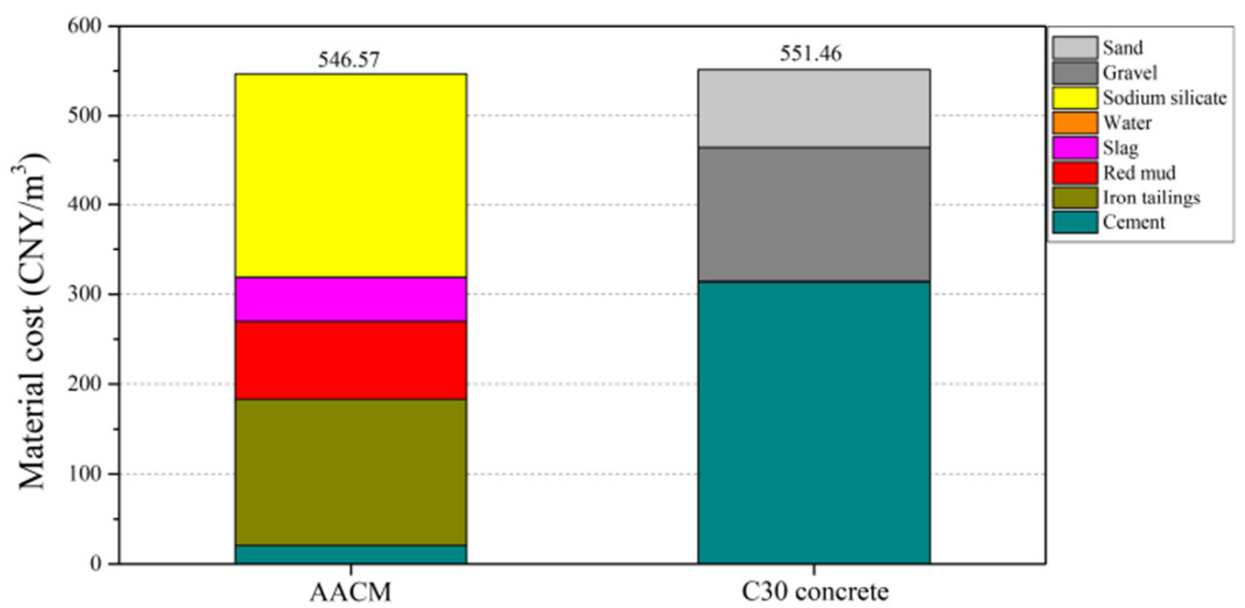

Figure 13. Embodied carbon and material cost of AACM. ((a): embodied carbon, (b): material cost).

Figure 13b shows material cost comparison between AACM and C30 concrete. It is known that the material cost of alkali-activated cement is generally higher than that of the 
traditional cement concrete at an equal strength level, mainly owning to the high cost of alkali activator. The material cost of AACM is calculated to be $546 \mathrm{CNY} / \mathrm{m}^{3}$. Although the cost of alkali activator accounts for $41.6 \%$ of the total material cost, this AACM attains lower materials cost than the reference $\mathrm{C} 30$ concrete. It suggests that using iron tailings as aggregates, red mud, blast furnace slag, and a small amount of Portland cement as precursors to prepare AACM has a certain economic potential.

\section{Conclusions}

In this work, the C-A-S-H gel formation mechanism, pore structure characteristics, environmental impact and economic potential of Bayer red mud-iron tailings-based AACM were further investigated based on our published work [18]. In order to verify the strength development and the general reaction product of Bayer red mud-iron tailings-based AACM, the origins of red mud, iron tailings, and blast furnace slag have changed in the present work. The flexural and compressive strengths of the AACM prepared in this work reach 7.28 and $29.74 \mathrm{MPa}$ after 28 days of hydration, which are basically close to the 28-day strength reported in the literature [18]. The early-strength characteristic endows the red mud-iron tailings-based AACM potentially being applied as road repair materials.

FT-IR and SEM analysis results prove that the reaction product of this AACM is mainly C-A-S-H gel. ${ }^{29} \mathrm{Si}$ NMR analysis results indicate that the C-A-S-H gels in the AACM specimen hydrated for 7 days are mainly composed of $\mathrm{SiQ}^{3}$ and $\mathrm{SiQ}^{2}$ units, while they mainly contain $\mathrm{SiQ}^{3}$ structure at 28 days. With the extension of the hydration time from 7 to 28 days, the $\mathrm{RBO}$ value increases by $11.02 \%$, indicating a significant increase of $\mathrm{SiO}_{4}$ tetrahedron polymerization degree of C-A-S-H gels. After being hydrated for 28 days, the structure of C-A-S-H gels becomes more complicated with $\mathrm{SiQ}^{4}$ structure increased and $\mathrm{SiQ}^{2}$ structure decreased.

SEM observation shows that the iron tailings aggregates are closely connected and cemented by the reticular C-A-S-H gels. With the prolongation of hydration time from 7 to 28 days, the content of $\mathrm{Al}$ and $\mathrm{Na}+\mathrm{K}$ in the $\mathrm{C}-\mathrm{A}-\mathrm{S}-\mathrm{H}$ gel increases significantly, while the content of $\mathrm{Si}$ and $\mathrm{Ca}$ decreases correspondingly. Owing to the substitution of $\mathrm{Si}$ by $\mathrm{Al}$ in the C-A-S-H gel, the number of $\mathrm{AlO}_{4}$ connected with $\mathrm{SiO}_{4}$ increases with the extension of hydration time, and on this basis, the number of monovalent cations (such as $\mathrm{Na}^{+}$and $\mathrm{K}^{+}$) that attracted for solidification due to the charge vacancy also increases.

The formation mechanism of this AACM is clarified. When the alkali-activated reaction and hydration begin, the 52.5 Portland cement and sodium silicate solution quickly release ions of $\mathrm{Ca}^{2+}, \mathrm{OH}^{-},\left[\mathrm{H}_{3} \mathrm{SiO}_{4}\right]^{-}$. Under the activation provided by the 52.5 Portland cement and alkali activator, $\left[\mathrm{H}_{3} \mathrm{SiO}_{4}\right]^{-}$and $\left[\mathrm{H}_{3} \mathrm{AlO}_{4}\right]^{2-}$ ions are continuously dissolved from the active $\mathrm{SiO}_{2}$ and $\mathrm{Al}_{2} \mathrm{O}_{3}$ in the red mud, blast furnace slag powder, and the surface of iron tailings. In this blended system, the amorphous C-A-S-H gels are formed by the reaction of $\left[\mathrm{H}_{3} \mathrm{SiO}_{4}\right]^{-}$and $\left[\mathrm{H}_{3} \mathrm{AlO}_{4}\right]^{2-}$ ions with $\mathrm{Ca}^{2+}$. In addition, as the hydration time increases, a large amount of dissolved $\mathrm{Na}^{+}$and $\mathrm{K}^{+}$can be stabilized in the amorphous C-A-S-H gels. $\mathrm{Na}^{+}$and $\mathrm{K}^{+}$play roles of catalysis and participation in charge balance in this reaction.

The data analysis results of X-CT show that the pore distribution of the AACM is relatively uniform, which is conducive to the development of mechanical strength. The pores in the AACM sample account for $6.73 \%$ of the total volume, and these pores are not connected. The minerals, aggregate particles, and other matrix materials account for $10.98 \%, 24.71 \%$, and $57.58 \%$ of the total volume, respectively. The total embodied carbon and material cost of AACM are lower than those of the reference C30 concrete, demonstrating that the prepared AACM has great environmental benefit and certain economic potential.

The novelty of this work focuses on the explanation of the C-A-S-H gel formation mechanism in the red mud-iron tailings-based AACM and the clarification of its pore structure. It provides a theoretical support for the large-scale industrial utilization of iron tailings and red mud in the production of AACM. 


\begin{abstract}
Author Contributions: Investigation, Data Curation, Formal analysis, Writing-Original Draft, C.L.; Validation, Data Curation, Formal analysis, Writing-Review and Editing, Supervision, N.Z.; Investigation, Data Curation, Formal analysis, J.Z.; Investigation, Data Curation, Formal analysis, S.S.; Conceptualization, Validation, Supervision, Y.Z. All authors have read and agreed to the published version of the manuscript.
\end{abstract}

Funding: This research was funded by the National Natural Science Foundation of China, project number 51974283, and Fundamental Research Funds for the Central Universities, project number 2652019034.

Institutional Review Board Statement: Not applicable.

Informed Consent Statement: Not applicable.

Data Availability Statement: Date sharing is not applicable to this article.

Conflicts of Interest: The authors declare no conflict of interest.

\title{
References
}

1. Solymar, K.; Sajo, I.; Steiner, J.; Zoldi, J. Characteristics and separability of red mud. Light Met. 1992, $209-223$.

2. Liu, W.C.; Chen, X.Q.; Li, W.X.; Yu, Y.F.; Yan, K. Environmental assessment, management and utilization of red mud in China. J. Clean. Prod. 2014, 84, 606-610. [CrossRef]

3. Wang, S.H.; Jin, H.X.; Deng, Y.; Xiao, Y.D. Comprehensive utilization status of red mud in China: A critical review. J. Clean. Prod. 2021, 289, 2-3. [CrossRef]

4. China Industry Information. 2019. Available online: https://www.chyxx.com/industry/201906/750518.html (accessed on 23 November 2020).

5. Xue, Y.; Liu, X.M. Detoxification, solidification and recycling of municipal solid waste incineration fly ash: A review. Chem. Eng. J. 2021, 420, 2-9. [CrossRef]

6. Song, S.Q.; Zhou, Y.Z. Mining wasteland and its ecological restoration and reconstruction. Conserv. Util. Miner. Resour. 2001, 5 , $44-45$.

7. Han, F.H.; Li, L.; Song, S.M.; Liu, J.H. Early-age hydration characteristics of composites binder containing iron tailing powder. Powder Technol. 2017, 315, 322-331. [CrossRef]

8. Zhang, N.; Tang, B.W.; Liu, X.M. Cementitious activity of iron tailing and its utilization in cementitious materials, bricks and concrete. Constr. Build. Mater. 2021, 288, 123022. [CrossRef]

9. Zhang, S.; Xue, X.; Liu, X.; Duan, P.; Yang, H.; Jiang, T.; Wang, D.; Liu, R. Current situation and comprehensive utilization of iron ore tailing resources. J. Min. Sci. 2006, 42, 403-408. [CrossRef]

10. Adamo, N.; Al-Ansari, N.; Sissakian, V.; Laue, J.; Knutsson, S. Dam safety: The question of tailings dams. J. Earth Sci. Geotech. Eng. 2021, 11, 1-26. [CrossRef]

11. Davidovits, J. Geopolymers-Inorganic polymeric new materials. J. Therm. Anal. 1991, 37, 1633-1656. [CrossRef]

12. Liu, J.P.; Li, X.Y.; Lu, Y.S.; Bai, X.H. Effects of Na/Al ratio on mechanical properties and microstructure of red mud-coal metakaolin geopolymer. Constr. Build. Mater. 2020, 263, 2-9. [CrossRef]

13. Koshy, N.; Dondrob, K.; Hu, L.M.; Wen, Q.B.; Meegoda, J.N. Synthesis and characterization of geopolymers derived from coal gangue, fly ash and red mud. Constr. Build. Mater. 2019, 206, 287-296. [CrossRef]

14. Duan, P.; Yan, C.J.; Zhou, W.; Ren, D.M. Fresh properties, compressive strength and microstructure of fly ash geopolymer paste blended with iron ore tailing under thermal cycle. Constr. Build. Mater. 2016, 118, 76-88. [CrossRef]

15. Defáveri, K.; Santos, L.; Carvalho, J.; Peixoto, R.F.; Brigolini, G.J. Iron ore tailing-based geopolymer containing glass wool residue: A study of mechanical and microstructural properties. Constr. Build. Mater. 2019, 220, 375-385. [CrossRef]

16. Chen, Y.L.; Wu, S.Y.; Qi, C.H.; Xiao, H.P.; Xie, Y.B.; Wang, M.C. Formula optimization and mechanism of preparing geopolymers based on iron tailings and metakaolin. Metal Mine 2019, 4, 199-203.

17. Wang, Y.G.; Liu, X.M.; Zhang, W.; Li, Z.P.; Zhang, Y.L.; Li, Y.; Ren, Y.Y. Effects of Si / Al ratio on the efflorescence and properties of fly ash based geopolymer. J. Clean. Prod. 2020, 244, 118852. [CrossRef]

18. Song, S.; Zhang, N.; Yuan, J.B.; Zhang, Y.H. New attempt to produce red mud-iron tailing based alkali-activated mortar: Performance and microstructural characteristics. J. Build. Eng. 2021, 43, 103222. [CrossRef]

19. GB/T17671-1999Test Method for Strength of Cement Mortar, Chinese Standard Press: Beijing, China, 1999.

20. Emile, M.; Liu, X.M.; Zhang, L.L.; Zhang, N. Preparation and characterization of a red mud-based road base material: Strength formation mechanism and leaching characteristics. Constr. Build. Mater. 2019, 220, 297-307.

21. Zhang, N.; Liu, X.M.; Sun, H.H.; Li, L.T. Pozzolanic behavior of compound-activated red mud-coal gangue mixture. Cem. Concr. Res. 2011, 41, 270-278. [CrossRef]

22. Zhang, N.; Li, H.X.; Zhao, Y.Z.; Liu, X.M. Hydration characteristics and environmental friendly performance of a cementitious material composed of calcium silicate slag. J. Hazard. Mater. 2016, 306, 67-76. [CrossRef] 
23. Liu, X.M.; Zhao, X.B.; Yin, H.F.; Chen, J.L.; Zhang, N. Intermediate-calcium based cementitious materials prepared by MSWI fly ash and other solid wastes: Hydration characteristics and heavy metals solidification behavior. J. Hazard. Mater. 2018, 349, 262-271. [CrossRef] [PubMed]

24. Zhang, Y.L.; Liu, X.M.; Xu, Y.T.; Tang, B.W.; Wang, Y.G. Synergic effects of electrolytic manganese residue-red mud-carbide slag on the road base strength and durability properties. Constr. Build. Mater. 2019, 220, 364-374. [CrossRef]

25. Andersen, M.D.; Jakobsen, H.J.; Skibsted, J. Incorporation of aluminum in the calcium silicate hydrate (C-S-H) of hydrated portland cements: A High-Field ${ }^{27} \mathrm{Al}$ and ${ }^{29} \mathrm{Si}$ MAS NMR Investigation. Inorg. Chem. 2003, 42, 2280-2287. [CrossRef] [PubMed]

26. Puertas, F.; Fernández-Jiménez, A.; Blanco-Varela, M.T. Pore solution in alkali activated slag cement pastes. Relation to the composition and structure of calcium silicate hydrate. Cem. Concr. Res. 2004, 34, 139-148. [CrossRef]

27. Ding, Z.; Hong, X.; Zhu, J.X.; Tian, B.Y.; Fang, Y. Alkali-activated red mud-slag cementitious materials. J. Chin. Electron Microsc. Soc. 2018, 37, 149-150.

28. Bayat, A.; Hassani, A.; Yousefi, A.A. Effects of red mud on the properties of fresh and hardened alkali-activated slag paste and mortar. Constr. Build. Mater. 2018, 167, 775-790. [CrossRef]

29. Wang, S.D.; Scrivener, K.L. Hydration products of alkali activated slag cement. Cem. Concr. Res. 1995, 25, 561-571. [CrossRef]

30. Ye, N.; Yang, J.K.; Liang, S.; Hu, Y.; Hu, J.P. Synthesis and strength optimization of one-part geopolymer based on red mud. Constr. Build. Mater. 2016, 111, 317-325. [CrossRef]

31. Kubicki, J.D.; Apitz, S.; Blake, G. G2 theory calculations on $\left[\mathrm{H}_{3} \mathrm{SiO}_{4}\right]^{-},\left[\mathrm{H}_{4} \mathrm{SiO}_{4}\right],\left[\mathrm{H}_{3} \mathrm{AlO}_{4}\right]^{2-}$, $\left[\mathrm{H}_{4} \mathrm{AlO}_{4}\right]^{-}$and $\left[\mathrm{H}_{5} \mathrm{AlO}_{4}\right]$ : $\mathrm{Basis}$ set and electron correlation effects on molecular structures, atomic charges, infrared spectra, and potential energies. Phys. Chem. Miner. 1995, 22, 481-488. [CrossRef]

32. Wang, Q.; Kang, S.R.; Wu, L.M.; Zhang, Q.; Ding, Z.Y. Structural modeling and molecular dynamics simulation of geopolymers gel. Mater. Rep. 2020, 34, 04056-04058.

33. Inés, G.; Shane, D.; Ana, F.; Ángel, P. Hydration of hybrid alkaline cement containing a very large proportion of fly ash: A descriptive model. Materials 2016, 9, 5-10.

34. Tao, W.H.; Fu, X.H.; Sun, F.J.; Yang, Z.X. Studies on properties and mechanism of geopolymer cementitious material. Bull. Chin. Ceram. Soc. 2008, 27, 730-739.

35. Ye, N.; Chen, Y.; Yang, J.K.; Liang, S.; Hu, Y. Transformation of Na, Al, Si and Fe species in red mud during synthesis of one-part geopolymers. Cem. Concr. Res. 2017, 101, 123-130. [CrossRef]

36. Tang, B.W.; Gao, S.; Wang, Y.G.; Liu, X.M.; Zhang, N. Pore structure analysis of electrolytic manganese residue based permeable brick by using industrial CT. Constr. Build. Mater. 2019, 208, 697-709. [CrossRef]

37. Wan, J.B.; Sun, B.D.; Chen, S.J.; Du, H.H.; Zhang, L. Digital core technology research and its applications. Well Logging Technol. 2012, 36, 154-159.

38. Arand, F.; Hesser, J. Accurate and efficient maximal ball algorithm for pore network extraction. Comput. Geosci. 2017, 101, 28-37. [CrossRef]

39. Yu, J.; Mishra, D.K.; Hu, C.L.; Leung, K.Y.; Shah, S.P. Mechanical, environmental and economic performance of sustainable Grade 45 concrete with ultrahigh-volume Limestone-Calcined Clay (LCC). Resour. Conserv. Recycl. 2021, 175, 105846. [CrossRef]

40. Hammond, G.; Jones, C. Inventory of Carbon and Energy, 3rd ed.; University of Bath: Bath, UK, 2019.

41. GB 50010-2010Code for Design of Concrete Structures, Chinese Standard Press: Beijing, China, 2010. 